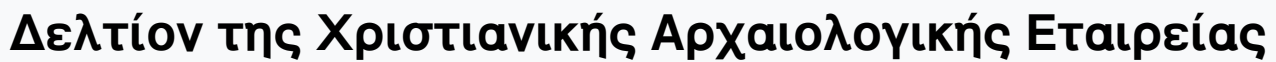

Tó 25 (2004)

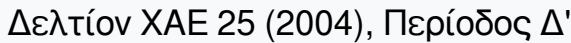

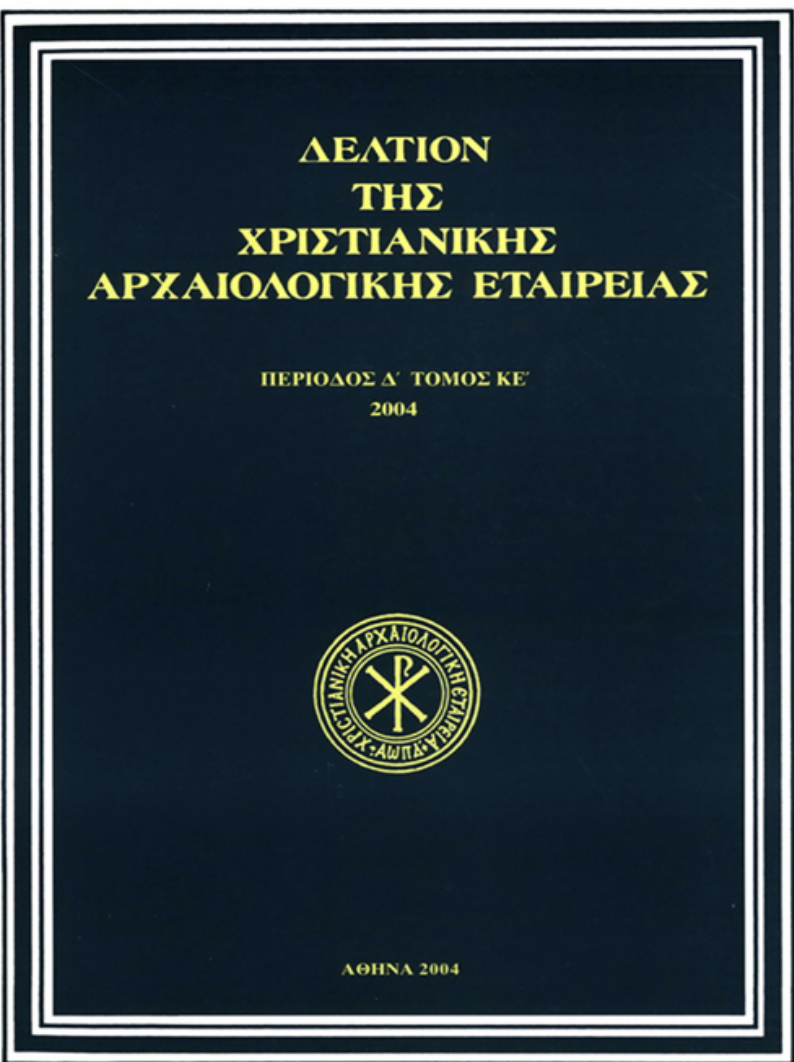

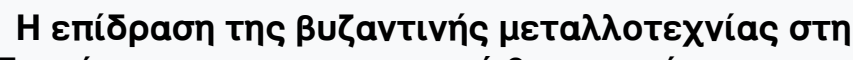

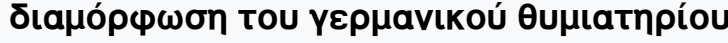

Ellen C. SCHWARTZ

doi: $10.12681 /$ dchae.417

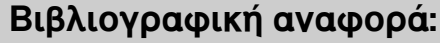

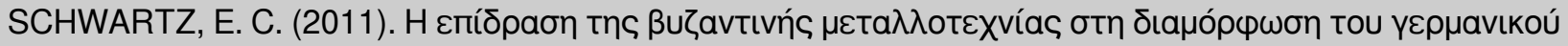

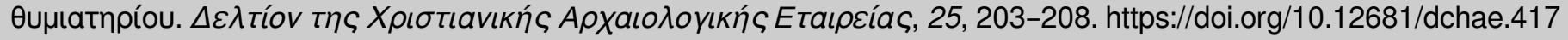




\section{$\triangle \mathrm{E} \Lambda \mathrm{TION}$ TH $\Sigma$ XPI $\Sigma$ TIANIKH $\Sigma$ APXAIO $\Lambda$ OГIKH $\Sigma$ ETAIPEIA $\Sigma$}

Under the Influence: Byzantine Metalwork and the Development of the German Censer

Ellen SCHWARTZ

Tómos KE' (2004) • $\Sigma \varepsilon \lambda . ~ 203-208$

A@HNA 2004 


\author{
Ellen C. Schwartz
}

\title{
UNDER THE INFLUENCE: BYZANTINE METALWORK AND THE DEVELOPMENT OF THE GERMAN CENSER
}

$\mathrm{O}_{\mathrm{t}}$ ten overlooked, ordinary liturgical objects of early medieval art may hold the key to many problems of Byzantine artistic influence in metalwork and other media. A small censer in the Malcove Collection at the University of Toronto will serve as an example (Fig. 1). Sheila Campbell originally published the censer as object no. 388 in the catalogue of the Malcove Collection, 1985. She identified it as a censer of western type with Byzantine or Coptic-influenced decoration, tentatively dated into the eleventh-twelfth century with Italy as a suggested provenance ${ }^{1}$. It was later published in the catalogue of the exhibition I co-curated with Thelma K. Thomas at the University of Michigan Museum of Art, "Beyond Empire: Artistic Expressions of Byzantium"2. While a modest piece, the censer is typical of these small, portable objects which, free of the iconographic determinism of so much medieval art, may allow us to deal more purely with cross-cultural interchanges in terms of type, technique, and style.

The censer is made of bronze. In good condition, albeit without its chains, it measures $16.5 \times 12 \mathrm{~cm}$ in size. Its slightly ovoid body consists of two parts: an upper portion slightly larger than half the height, and a lower one correspondingly smaller on a short flaring foot. The bottom part and the foot

1. Sheila D. Campbell (ed.), The Malcove Collection. A Catalogue of the Objects in the Lillian Malcove Collection of the University of Toronto, Toronto 1985, no. M82.413, p. 285. My thanks to Dr. Campbell for the photograph of this censer and the other objects from the Malcove Collection used in this article.

2. Beyond Empire: Artistic Expressions of Byzantium, exhibition catalogue, Ann Arbor 1994, see Ellen C. Schwartz and Thelma K. Thomas, entry 6, "Censer with Byzantine-Inspired Decoration". A preliminary version of this study was presented at the concurrent XX Byzantine Studies Conference, October 1994; an abstract is published in the abstracts volume of the conference, 57-58.

3. Anna Gonosova and Christine Kondoleon, Art of Late Rome and Byzantium in the Virginia Museum of Fine Arts, Richmond 1994, censer no. $67-27$, p. 274-77. Censers such as this may be dated by comparison to silver ones with the ever-convenient stamps which bear datable have triangular perforations which, in their point up/point down alternation, form a patterned band running around each section, as well as at the top. The larger upper part is pierced by a series of keyhole-shaped openings with rectangular ends. Over these and stacked between them are double incised concentric circles, each with a dot at the center. This upper part ends in a conical protrusion consisting of inward-leaning slabs, topped by a truncated cross. The censer was suspended by chains which attached to the perforations in the three sets of matched loops at the censer's middle. The chains ran through the doubled loops, allowing the top to slide up on the chains for filling and be held in place as the censer was swung. A fourth chain was probably attached to the top, as well.

The Malcove censer is clearly of western rather than Byzantine type. Comparison to the many bronze Byzantine censers which survive, along with depictions in monumental art, make this clear ${ }^{3}$. These Byzantine censers are open, with faceted, bulbous or cylindrical bodies, and swing from three chains which are attached to the rim. A preference for this open type continues in the east into middle and late Byzantine times ${ }^{4}$.

Western censers, on the other hand, take a different form.

monograms of rulers' names; see Erica Cruikshank Dodd, Byzantine Silver Stamps, Washington, D.C. 1961, fig. 35, p. 130-31. The use of these stamps for dating is discussed in Part II of the above mensioned volume. The issue of silver stamps was reopened in several papers from the 1986 symposium, published in Susan A. Boyd and Marlia Mundell Mango, Ecclesiastical Silver Plate in Sixth-Century Byzantium, Washington, D.C. 1992. Contemporary censers are depicted in monumental art as well, such as the one in the well-known Justinian panel from San Vitale, pictured in Fred S. Kleiner et al., Gardner's Art Through the Ages, Fort Worth 2001, fig. 12.10. 4. Representations of similar censers occur in later works such as the mosaics at Daphni, ca. 1100 (Otto Demus, Byzantine Mosaic Decoration, Boston 1955, pl. 4) and the Menil St Stephen icon, from the first quarter of the fourteenth century (Ellen C. Schwartz, The Saint Stephen Icon, in Bertrand Davezac (ed.), Four Icons in the Menil Collection, Houston 1992, 46-55). 


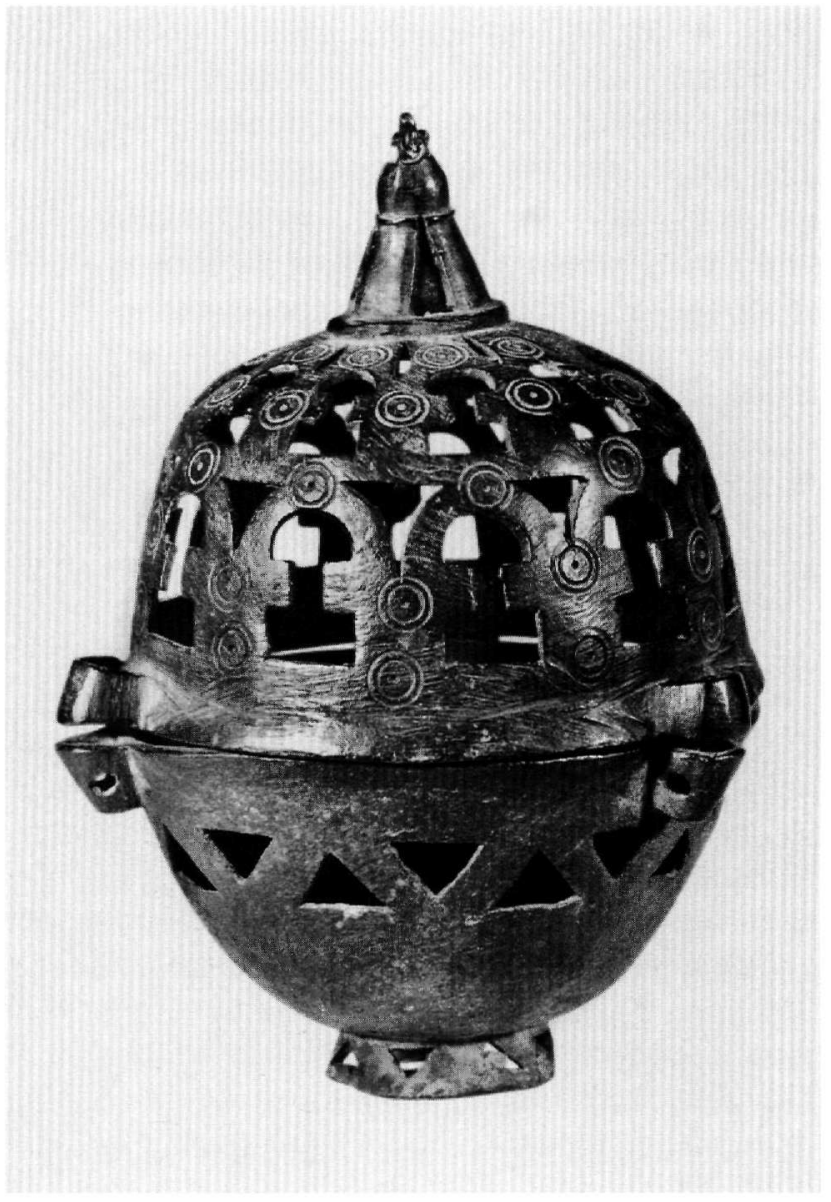

Fig. 1. Bronze censer, Malcove Collection, Toronto, no. M82.413. German, twelfth century.

The covered type is more popular there, and appears from early medieval times onward, as evidenced by many actual examples and representations in two-dimensional art. The almost spherical type of the Malcove censer is prominent among these. Examples are seen depicted in a fresco of St Clement performing mass from the lower church of San Clemente, Rome, late eleventh century, and in a twelfthcentury walrus ivory carving from Germany ${ }^{5}$.

While the Malcove censer shares some of the overall characteristics such as shape and simple geometric openings with some of the pieces considered above, it has none of the elaboration and complexity of decoration. Rather, the Malcove censer presents a very different appearance. Much of the impact of this piece is created by the prominance of the surface which is dark, smooth, and almost shiny. The openings of unusual shape read as holes pierced in a taut membrane, rather than as openings in a miniature wall or lattice. A similar relationship among tight shape, taut surface and pierced openings is seen in several censers originating in Germany in the twelfth century. One in the Metropolitan Museum (no. 09.152.6) has openings which are appropriately cruciform (Fig. 2) ${ }^{6}$. An example from the Treasury of Trier (no. 51) shows again the distorted spherical body, smooth prominent surface, and geometric cut-outs (Fig. 3) ${ }^{7}$. The triangular openings on the lower portion of this censer, in fact, are identical to those on the Malcove piece, both in their shape and their patterning. Such close similarities help to support a new provenance, Germany, and a firmer dating into the twelfth century for the censer under consideration.

Even with its clarified dating and provenance, the Malcove censer allows consideration of another, broader issue with the problem of its decoration. The prominent embellishment on the top - the incised circles and the more unusual keyhole apertures - point to the direct influence of Byzantine metalwork. The incised double circles are easily identified, as they are a fairly common decorative and sometimes apotropaic device used on Byzantine metal, wooden, earthenware and bone objects of liturgical and personal use. Easily produced with a compass which may also provide a central dot, the concentric circle motif shows up on various items such as combs, dolls, toys, pyxides, shrines, amulets
5. The fresco is published in Otto Demus, Romanische Wandmalerei, Munich 1968, pl. XVI. The ivory may be found in Anton Legner, Deutsche Kunst der Romanik, Munich 1982, fig. 387. This body shape persists, in fact, through high medieval Europe; one can be seen in a window from St Magadalen bei Weitensfeld in Gurktal, from the last quarter of the twelfth century and now in the Fürstbischöfliches Diozesanmuseum, Klagenfurt (ibid., fig. 166), and another appears in a stained glass window from Soissons dated ca. 1205-1212, today in the
Detroit Institute of Arts; see Julia P. Henshaw (ed.), Detroit Institute of Arts: $A$ Visitor's Guide, Detroit 1995, no. 59.34, p. 160.

6. Published by John H. Buck, BMMA IV, no. 11 (1909), 209.

7. Franz J. Ronig (ed.), Schatzkunst Trier, Trier 1984, no. 51, p. 117. Another smooth, pierced censer of spherical form from the same period is from the Schnütgenmuseum in Cologne, Joseph Braun S.J., Das christliche Altargerät, Munich 1932, fig. 507, pl. 128. 


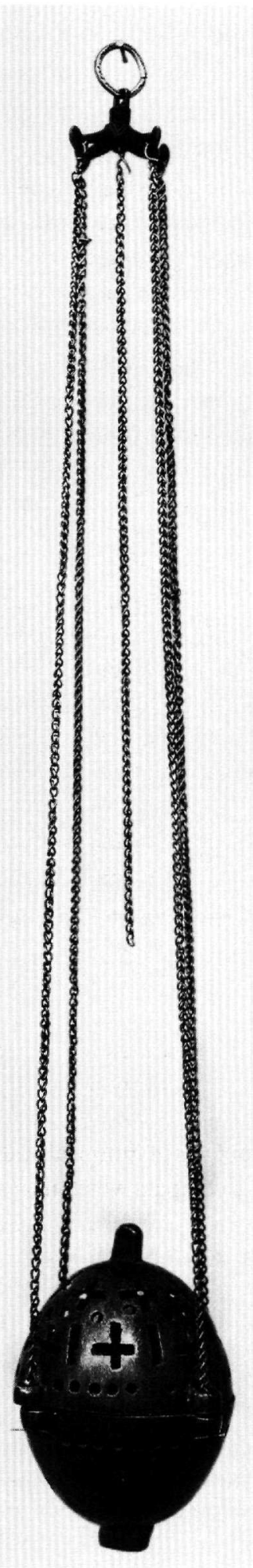

Fig. 2. Bronze censer, Metropolitan Museum of Art, New York, no. 09.152.6. German, twelfth century.

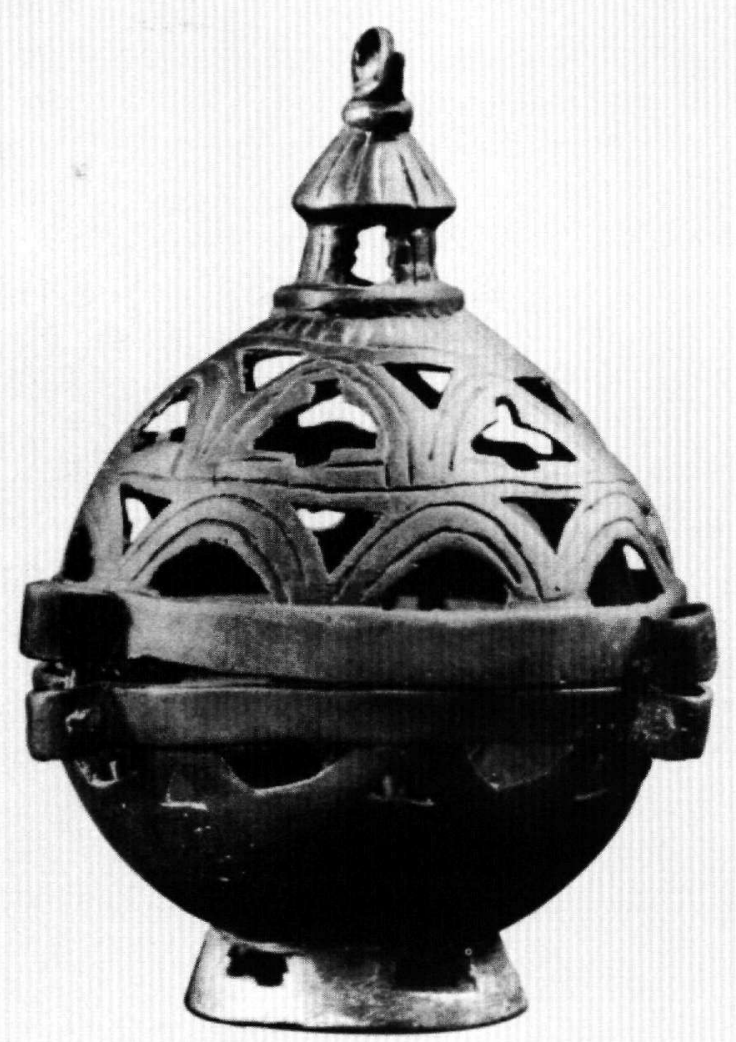

Fig. 3. Bronze censer, Treasury of Trier, no. 51. German, twelfth century.

and crosses of various sorts - pectoral, hanging, and processional (Fig. 4$)^{8}$. The concentric circles on our censer offer clear evidence of influence from portable objects originating in the Byzantine world.

The keyhole-shaped openings are rarer and more problematic. Given that holes are necessary for a censer to allow the passage of oxygen to fuel the burning of the coals, why was this unusual design chosen? Byzantine models again offer the answer. Keyhole-shaped openings do occasionally turn

8. See Campbell, op.cit. (n. 1), 115, as well as $113,123,125$; similar motifs decorate objects in Gonosova and Kondoleon, op.cit. (n. 1), 114-15. Eunice Dauterman Maguire et al., Art and Holy Powers in the Early Christian House, Urbana 1989, 6, 62, 168, 191-92, 218-19, 229 and 231; the origins and possible magical meaning of this motif are discussed on p. 5-7. 


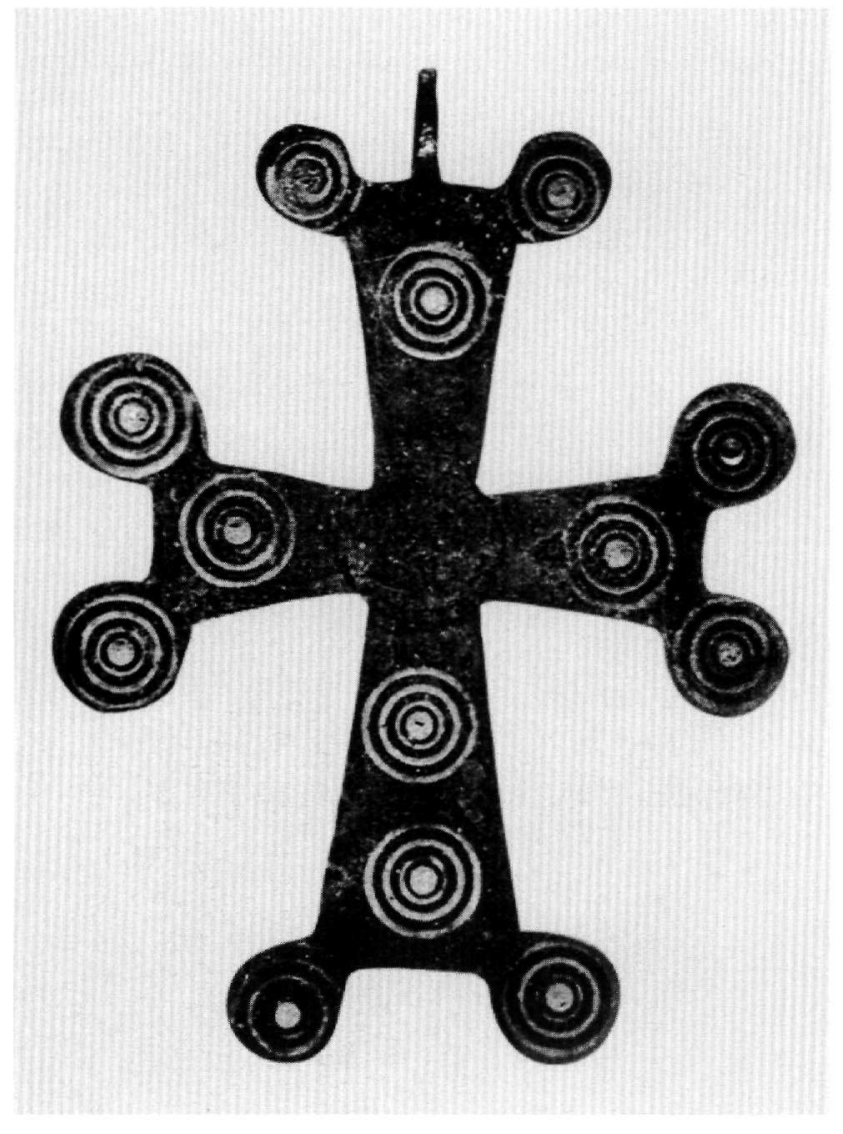

Fig. 4. Pectoral cross with concentric circle decoration, Malcove Collection, Toronto, no. M82.173. Coptic/Byzantine, sixth-eighth century (?).

up in Byzantine metalwork, notably in stands for processional crosses. The closest comparison is a cross stand from the Staatliche Museen, Berlin, no. 11/75, where the keyholeshaped top stands on a rectangular unit, almost identical to those on the censer's upper section (Fig. 5) ${ }^{9}$. This cross base and ones like it have been attributed to a Constantinopolitan workshop from the tenth to the eleventh century, a time frame that fits well with our reattribution of the censer's dating and place of origin. Other Byzantine cross stands may explain the origin of this unusual keyhole aperture. These bases, like one in the Malcove Collection, show keyholeshaped openings flanked by columns to create the effect of a horseshoe arch (Fig. 6). The structural elements which create the openings are part of an overall architectural framework of the stand, which gives the piece the form of a miniature building. The uppermost section looks like a tiny domed cross-in-square church in all these examples ${ }^{10}$. This architectonic conception may have had further influence in Germany, as well, for many extant censers there are created in a similar structural form, with the upper half articulated by gables, pinnacles, and holes which read as windows. The famous Gotburt censer from the twelfth century epitomizes this trend ${ }^{11}$. This custom been attributed to the twelfth-century writer Theophilus' instructions on censer-making which have been related to descriptions of the Heavenly Jerusalem $^{12}$, but this form may have been in part inspired by Byzantine art objects like the cross supports. A censer from Hentern, today in Trier, shows the keyhole openings, unframed as in the Malcove censer, within an architectural scheme - a possible bridge between these two groups of objects (Fig. 7) ${ }^{13}$. Others like the Hentern piece include a second Malcove censer, no. 387, which can now be reattributed to twelfth-century Germany on the basis of its similarity to the foregoing examples ${ }^{14}$. And such architectonic conceptions may be alluded to on the simpler censer as well; the aforementioned concentric circles may refer to bases and capitals of columns in their placement vis-à-vis the keyhole openings.

Byzantine influence, then, may have inspired artists and
9. Peter Bloch, Ex aere solido, Bronzen von der Antike bis zur Gegenwart. Eine Ausstellung der Stiftung Preussischer Kulturbesitz Berlin aus den Bestanden ihrer Staatlichen Museen, Berlin 1983, fig. 25, p. 48-50.

10. Campbell, op.cit. (n. 1), no. 179 on p. 127, accession no. M82.393. Other cross stands with similar forms are the one in the Dumbarton Oaks Collection, no. 40.14, John A. Cotsonis, Byzantine Figural Processional Crosses, Washington, D.C. 1994, fig. 39, as well as a second example at Dumbarton Oaks, no. 62.10.8. Similar, too, is a cross stand in Berlin, no. 6358, Das Museum für spätantike und byzantinische Kunst, Staatliche Museen zu Berlin, Berlin 1992, 233. Others have been catalogued and discussed Karl Ayers Sandin, Middle Byzantine Bronze Crosses of Intermediate Size: Form, Use and Meaning (Dissertation, Rutgers, The State University of New Jersey), New Brunswick, N.J. 1992,
258-284 and figs. 31-38; especially relevant are figs. 35 and 37.

11. Clemens M. M. Bayer, Zum Gotburters-Rauchfass in der Trierer Domschatzkammer, in Franz J. Ronig and Hans-Walter Stork (eds.), Schatzkunst Trier. Forschungen und Ergebnisse, Trier 1991, 45-88.

12. Theophilus, The Various Arts, trans. C.R. Dodwell, London 1961, xxvii-xxviii, 111-17. J. Tavenor-Perry, Dinanderie. A History and Description of Mediaeval Art Work in Copper, Brass and Bronze, New York 1910, 128-31.

13. Schatzkunst Trier (n. 11), figs. 15 and 16, p. 204-207. Architectural censers with cross- or quatrefoil-shaped openings which furnish additional links to the Malcove piece and its family are those from Freising and Munich, pictured in Braun, op. cit. (n. 7), figs. 522 and 524 of pl. 131. 14. Campbell, op.cit. (n. 1), no. M82.418, p. 284-85. 

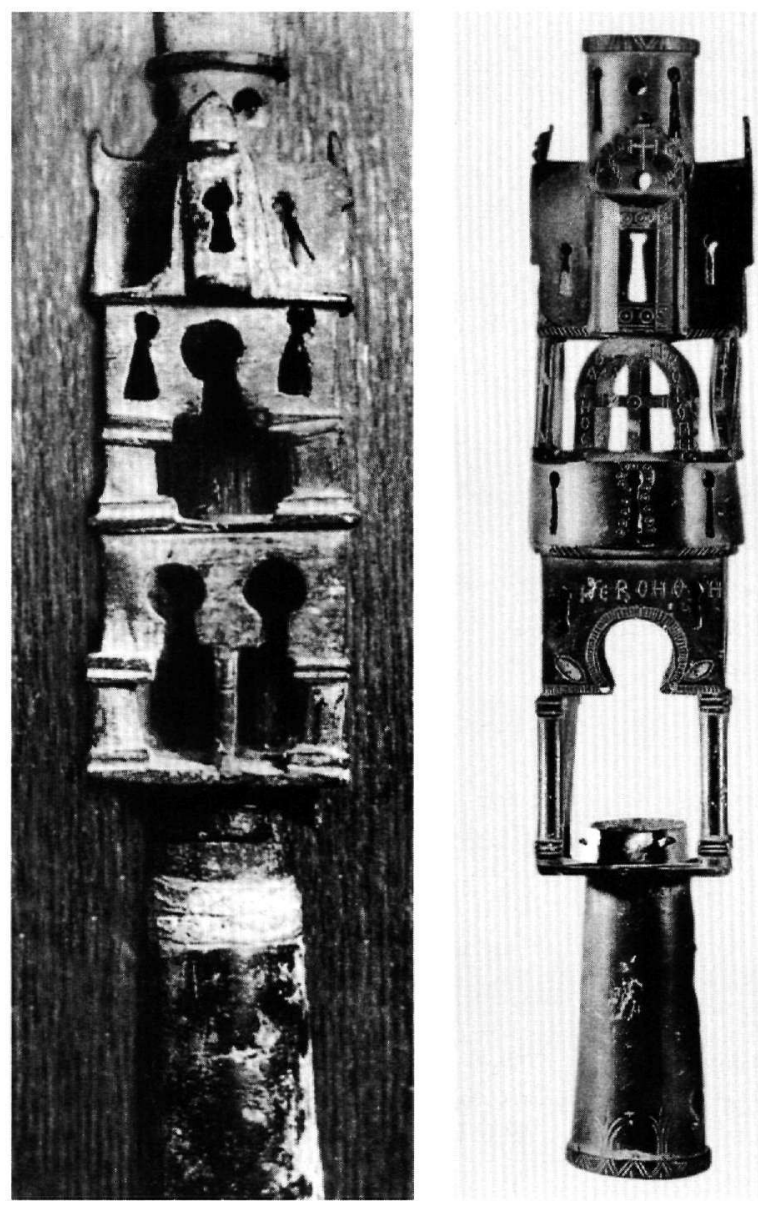

Fig. 5. Cross stand, Staatliche Museum, Berlin. Byzantine, tentheleventh century.

Fig. 6. Cross stand, Malcove Collection, Toronto, no. M82.393. Byzantine, tenth-eleventh century.

metalsmiths in several directions. The original transfer of artistic forms from Constantinople was undoubtedly occasioned by the marriage of German emperor Otto II to a Byzantine bride, Theophano, in 972, depicted in the wellknown ivory ${ }^{15}$. The impact of this marriage is well documented in thoroughly-studied architectural and figural arts. It is probable that the Orthodox Theophano's retinue contained more than just the manuscripts and ivories which had such a profound effect on Ottonian artistic produc-

15. Otto Demus, Byzantine Art and the West, New York 1970, fig. 80, p. 84-85; later considered by Charles T. Little in Helen C. Evans and William D. Wixom (eds.), The Glory of Byzantium, New York 1997, no. 337, p. 499-501.

16. Rosamond McKitterick, Ottonian intellectural culture in the tenth

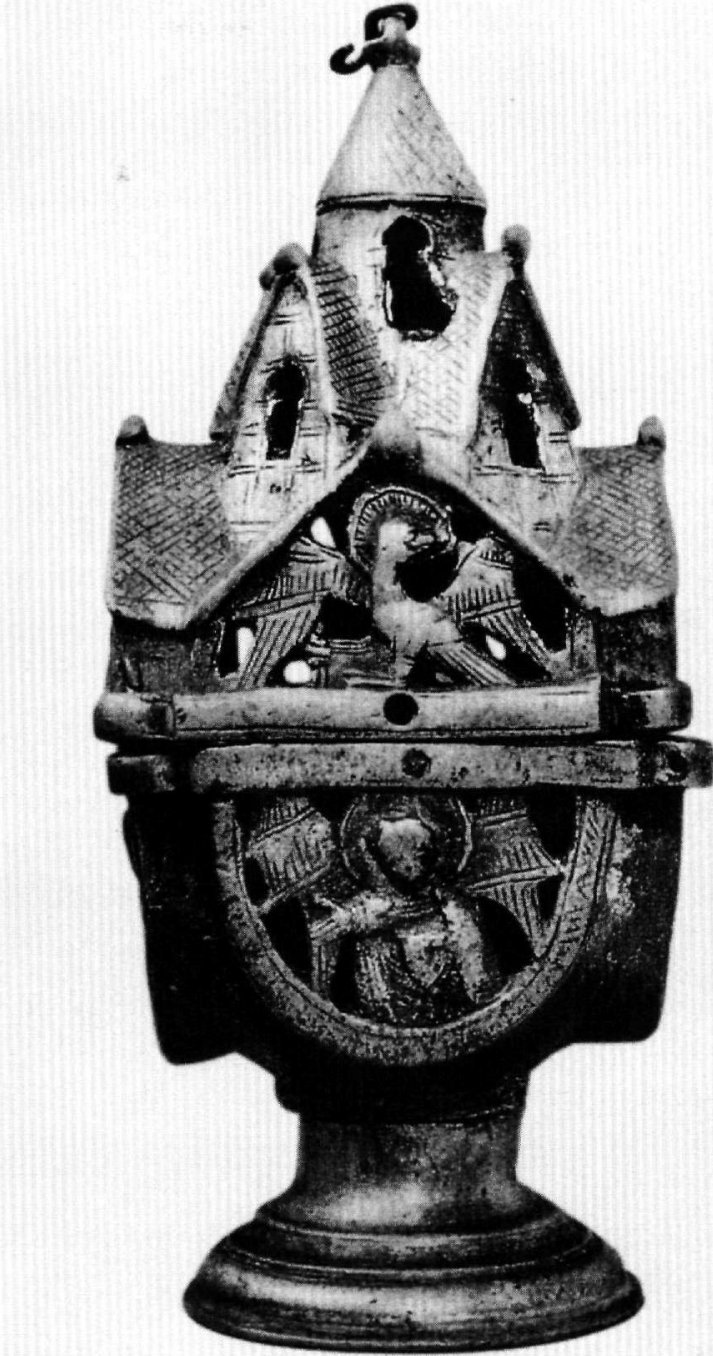

Fig. 7. Bronze censer, Hentern Collection, Trier. German, twelfth century.

tion $^{16}$. Undoubtedly there were countless necessary objects of liturgical, if not artistic, importance which came with her as well. These seem to have had a similar impact in providing fresh artistic directions for German artists. Of durable mate-

century and the role of Theophanu, Early Medieval Europe, II, 1, 1993, 55-74, with much relevant bibliography. My thanks to Alfred Buchler for

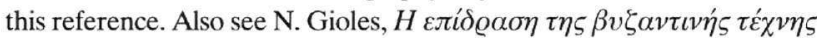

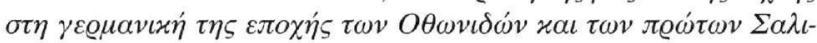

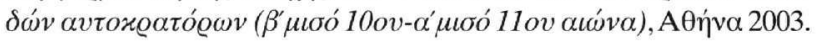


rials and liturgical efficacy, even in a Catholic context, these pieces seem to have offered inspiration over a long period of time. Perhaps objects such as the Malcove censer allow a glance through a different window onto this phenomenon of artistic influence. Here an unusual form, unassociated with specific religious meaning, may have been borrowed because of potential usefulness - iconographic or otherwise or even inherent visual interest. Indeed, the study of objects like this, despite their poor documentation and distinct lack of glamour, may elucidate even more of these borrowings, since in objects devoid of iconographic content questions of Orthodoxy and heresy were not at issue. Here we may find that criteria of utility and abstract aesthetic preference have also been subject to cross-cultural influences and thus may further serve to advance the quest for influence and reception and their meaning in the wider world of medieval culture and art.

Eastern Michigan University

\author{
Ellen C. Schwartz
}

\title{
H EПI $\triangle \mathrm{PA} \Sigma \mathrm{H}$ TH $\Sigma$ BYZANTINH $\Sigma$ META $\Lambda$ OTEXNIA $\Sigma$

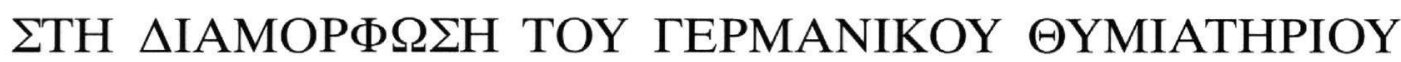

\begin{abstract}
'E

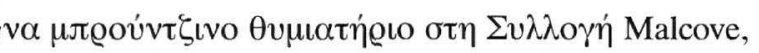

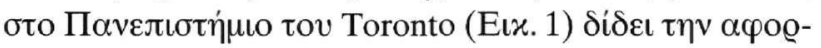

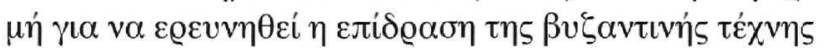

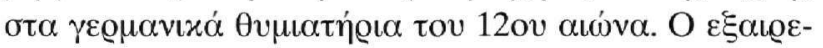

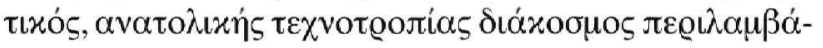

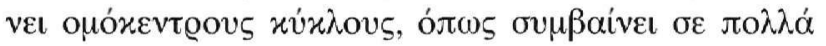

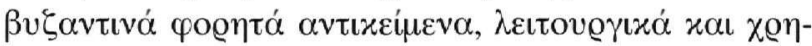

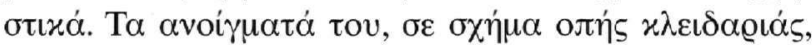

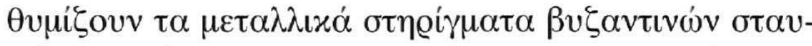

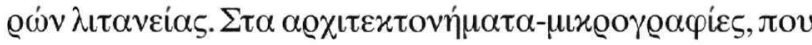

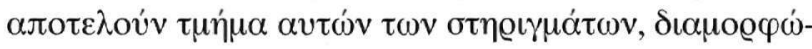

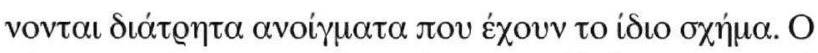

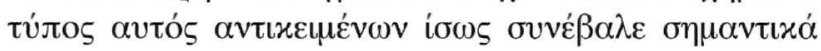

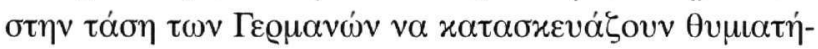

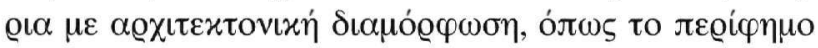
$\theta v \mu \iota \alpha$ t门่

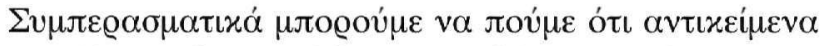

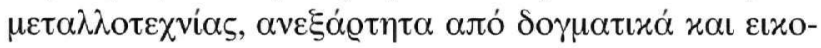

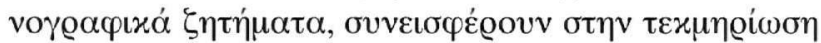

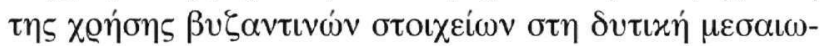

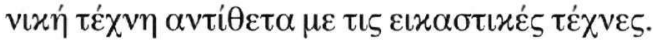

